\title{
O ETHOS DO JARDIM EM DORA RIBEIRO
}

\author{
ETHOS OF THE GARDEN IN \\ DORA RIBEIRO'S POEMS
}

\author{
Rauer Ribeiro RODRIGUES ${ }^{1}$ \\ Kelcilene GRÁCIA-RODRIGUES²
}

RESUMO: Ao lançar, em 2009, pela Companhia das Letras, a teoria do jardim, a poeta Dora Ribeiro, nascida em Campo Grande, MS, em 1960, e que estreou em 1984 com ladrilho de palavras, evidencia a sua peculiar trajetória autoral, marcada por poemas que edificam o eu-lírico na mesma medida em que, na aparência, se recusa a expor o sujeito biográfico. Seus versos, entre o simples e o inusitado, evidenciam a reflexão existencial e metapoética. Nosso esforço, nesse estudo, é o de delinear o ethos da teoria do jardim de Dora Ribeiro.

PALAVRAS-CHAVE: Literatura Brasileira; Metáfora; Poesia.

ABSTRACT: After lauching her book, A teoria do Jardim, by

${ }^{1}$ Programa de Pós-Graduação em Letras - Universidade Federal de Mato Grosso do Sul (UFMS), Campus de Três Lagoas - CEP 79603-011 — Três Lagoas - MS — Brasil. Email: rauer.rauer@uol.com.br.

${ }^{2}$ Programa de Pós-Graduação em Letras - Universidade Federal de Mato Grosso do Sul (UFMS), Campus de Três Lagoas - CEP 79603-011 - Três Lagoas — MS — Brasil. Email: kelcilenegracia@uol.com.br. 
RODRIGUES, R. R.; GRÁCIA-RODRIGUES, K. 0 ethos do jardim em Dora Ribeiro

Companhia das Letras Publishing House, Dora Ribeiro, poet who was born in Campo Grande MS, in 1960, and who started in literary world with the work Ladrilhos de palavras, in 1984, highlights her peculiar authorial career, marked by poems which build the I-lyrical and which, in their appearances, refuse to expose biographical subjects. Her verses, between simplicity and unusuality, demonstrate existencial and metapoetic reflections. Therefore, our effort, in this study, is to determine the ethos of Dora Ribeiro's book A teoria do Jardim.

KEYWORDS: Brazilian Literature; Metaphor; Poetry.

Dora Ribeiro, nascida em Campo Grande, MS, em 1960, tem sete livros publicados: ladrilho de palavras (1984), começar e o fim (1990), bicho do mato (2000), taquara rachada (2002), o poeta não existe (2005), a teoria do jardim (2009) e olho empírico (2011). Ao longo de sua vida literária, Dora Ribeiro recebeu elogios de Silviano Santiago (1984), Carlito Azevedo (2000), Flora Sussekind (1999), Luiz Costa Lima (2002), entre outros.

Ao lançar, em 2009, pela Companhia das Letras, a teoria do jardim, a poeta Dora Ribeiro deu sequência à sua peculiar trajetória autoral, marcada por poemas que edificam o eu-lírico na mesma medida em que, na aparência, se recusa a expor o sujeito biográfico. Seus versos, entre o simples e o inusitado, evidenciam a reflexão existencial e metapoética que norteiam a feitura do discurso, e essa trajetória meditada se traduz na escolha do título, pois o sema “jardim”, metáfora usual de espaço livre e de devaneios, no qual os desejos se manifestam, se vê condicionado e, aparentemente, constrangido - pelo sema "teoria”, palavra que carrega conotações de estudo, aplicação, sistematização lógica.

Já a capa do livro, assinada por "warrakloureiro", evidencia a escolha 
de sempre, da autora, por grafar até mesmo o próprio nome sempre com minúsculas. 0 grafismo mostra um labirinto, dotado de um centro irradiador para o qual convergem todos os caminhos, como a evidenciar, nos múltiplos becos, um eu irresoluto, mas medido, convulso, porém racional. A última capa reproduz o décimo-nono poema do livro: ${ }^{3}$

\author{
o traçado do teu jardim \\ ignora parágrafos \\ para avançar nas \\ delicadezas do imprevisto \\ e da inexatidão \\ à procura do engenho do desejo \\ invoco a ingenuidade do belo: \\ deslizante caça dialética
}

(RIBEIRO, 2009, p. 28).

Se o poema eleito para figurar o conjunto da obra esconde o núcleo do título, expresso por "a teoria”, nosso esforço, nesse estudo, é o de delinear o ethos da teoria do jardim de Dora Ribeiro. Nosso método é o do garimpeiro, lançando à bateia os poemas e colhendo os versos que faiscarem respostas ao nosso problema. Intuímos que a teoria proposta pela poeta se dá por sucessivas ressemantizações do conceito de Jardim.

\title{
O Jardim mítico e o jardim primordial
}

A palavra Jardim tem significados que remetem à aurora dos tempos.

Antes de ser um espaço de beleza planejada, urbanizada, o Jardim tem caráter mítico, seja na invocação pagã dos deuses clássicos, seja no desejo de prazer cantado por Khayamm, seja no éden hebraico-cristão,

\footnotetext{
${ }^{3}$ Somente dezenove poemas do livro, composto por 75 poemas, têm títulos. Os poemas estão distribuídos em três partes, a primeira sem título, a segunda nomeada como "a paisagem do corpo", e a terceira como "systema naturae, classificação das coisas vivas".
} 
seja no espaço propício à meditação solitária de civilizações orientais, seja no céu com rios de leite e mel para o prazer eterno dos fieis. 0 Jardim mítico pesa sobre os ombros da palavra dicionarizada, pois os sucessivos significados do vocábulo, sem eliminar os anteriores, acrescentam novas acepções.

Desse modo, o Jardim se torna espaço em que convivem o recolhimento e a sensualidade, o celestial e o carnal, o profano e o epifânico, o temporal e o eterno. Esse Jardim, complexo, porém acessível, parece negar-se a racionalizações, pois oscila entre dois pólos antitéticos, ambos pouco suscetíveis a apelos cartesianos: o corpo sensível, comandado pela passion, e a fé revelada, sob o domínio de dogmas e do mistério. ${ }^{4}$

Dora Ribeiro dialoga com esse Jardim múltiplo, oriundo do que é arquetípico, mas devedor das camadas de sentido que o tempo lhe depositou, como se fora um palimpsesto em que as novas escrituras não derrogam as anteriores, antes as evidenciam em sua simultaneidade. Ela o faz no poema intitulado "terreno primordial":

na véspera de tudo
o melhor é ficar em casa
e rasgar o chão
os olhos dos caminhos
as dilatadas fomes
tudo o que possa clarificar
as ausências e os medos
na véspera do mundo
todas as ruas são construções
sem cheiro
sem sexo
na véspera do jardim
fico imaginando
um tempo cromossômico
sem a tua insinuação biloba

(RIBEIRO, 2009, p. 37).

\footnotetext{
${ }^{4}$ Seria a poesia de Dora uma tentativa de conciliar fé, corpo e razão? Eis uma interessante questão a ser pesquisada em outro momento.
} 
Temos aqui não o Jardim, mas um "terreno" que simboliza a "véspera de tudo": "na véspera do mundo / todas as ruas são construções / sem cheiro / sem sexo". O primordial se anuncia, pois, como um antes "de tudo", até mesmo "do mundo".

0 mundo, no entanto, já aí está, com suas ruas, mesmo na véspera de si mesmo. Como construção, indica que a existência primordial é ao mesmo tempo sensível e inteligível, apreende-se pelos sentidos e pelos sentimentos, mas se corporifica pela inteligência que a nomeia. Tanto que, "na véspera de tudo / o melhor é ficar em casa"; essa casa, os versos seguintes a desvelam mais como simbólica que real, pois que significa "rasgar o chão / os olhos dos caminhos". 0 terreno surge, assim, como trajetória palmilhada em "dilatadas fomes".

Rasgar, olhar e ter fome são reunidos em um anafórico "tudo", do verso "tudo o que possa clarificar". Desse modo, tato, visão, sabor, desejo, ação, todo um conjunto sensório se volta para, de cunho intelectivo, o "clarificar / as ausências e os medos". O primordial que emerge dos versos é dolorido, em universo em que predomina o medo e o sentimento de ausência. Note-se, aqui, que o "ausências" não indicia solidão, pois que estar só é contingência humana, enquanto as ausências no terreno primordial parecem ontológicas, delas não se podendo escapar.

As ruas construídas, que marcam o social ordenado, fazem o espaço da casa, da primeira estrofe, transitar, na segunda estrofe, para o espaço da convivência humana na urbes. Mas o mundo ainda não existe, as ruas não têm cheiro, nelas não há ainda o sexo. Se as fomes do cenário do domus levam a medos que precisam ser clarificados, a polis "sem cheiro / sem sexo" esclarece a busca empreendida pelo eu-lírico, o desejo que nele lateja desde o início do poema, aquilo que o faz "rasgar o chão" e vivenciar "dilatadas fomes".

Tendo assim esclarecido seu percurso, a trajetória da construção de sua identidade em um mundo na véspera de ser mundo, "na véspera de tudo", a poeta se aproxima do sentido de existir, "na véspera do jardim". 
Eis que o primevo Jardim se consubstancia como "jardim" imaginado, um jardim futuro, um terreno primordial no qual tomará corpo os caminhos e as fomes, no qual a ausência e o medo, clarificados, inexistam, pois que se trata, na imaginação discursivizada pelo eu-lírico, de "um tempo cromossômico". É, pois, um cronotopo sem referente histórico, na estrutura dos gens, no nascimento seminal de "tudo", pois que na véspera dessa aurora. 0 primordial, o gênico, o ontológico, o histórico e o futuro são presentificados, tornam-se hic et nunc do eu-lírico.

Desse modo, o eu-lírico se anuncia demiurgo, pelo desejo, pela sensualidade que lhe extravasa do corpo, pela razão e pela imaginação: a poeta constrói seu jardim a partir de um pretérito celular biológico, no cerne vital do existir e se replicar. Ao impedir que o tu invocado no último verso participe do jardim criador, a poeta firma sua constituição divinatória, negando ao "biloba", aquele que se insinua com dois globos, parte no festim da carne.

Desse modo, o eu-lírico é panteísta e no "terreno primordial”, universo de assexualidade, o desejo lateja irresolvido, "na véspera do jardim".

\title{
0 caminho como construção
}

No "terreno primordial” de Dora Ribeiro existe uma aparente oposição entre casa e rua. No entanto, no interior da casa existe um chão a ser rasgado, existem "caminhos". Casa e rua são construtos, e o caminho parece se delinear como uma construção, um desafio, uma trajetória que seduz e amedronta o eu do poema. Tal problemática surge, no livro, já no primeiro poema, sem título, cujo primeiro verso é "girassol":

\author{
girassol \\ abre os braços a cada manhã \\ pensando no caminho \\ e no avesso dele \\ nas turvas tarefas
}


que esgotam o seu sangue

e o meu sexo

tanta luz concentrada

numa ideia apenas

tanta miséria retida

em tão curto espaço de vida

girassol

gira loucamente

gira

porque não há sentido fora

do movimento e não existe

vida fora das breves inclinações

(RIBEIRO, 2009, p. 11).

Trata-se, aquele "girassol" do primeiro verso, de uma invocação, sendo ambiguamente sujeito dos outros seis versos que compõem a primeira estrofe. 0 girassol fica "[...] a cada manhã / pensando no caminho / e no avesso dele". Ao representar o girassol como interlocutor de si mesmo, o eu-lírico o vê em trajetória dúplice, que preenche tanto o caminho quanto o avesso desse caminho. Não se trata de trajetória cumprida, mas imaginada, e que se realizará por "turvas tarefas", que esgotam sangue e sexo.

A segunda estrofe esclarece, com dois enigmas poéticos, os caminhos e as tarefas, nomeando-os como "tanta luz concentrada / numa ideia apenas" e como "tanta miséria retida / em tão curto espaço de vida". Temos, pois, um motivo único como aquele que é o desígnio vital renovado "a cada manhã", e ele é portador de "luz concentrada", representando "curto espaço de vida"; no entanto, o qualificativo determinante é o de que é "tanta miséria retida".

No sangue que escoa do girassol fálico que torna-se flácido, na vida concentrada que se esgota e deixa exangue o sexo do eu-lírico, a fixação realizadora do ato sexual, vida que se realiza no movimento sem o qual não há vida, o poema se realiza como canto da exaustão do jardim: a miséria que sobrevém é a vida sem o movimento do ato sexual. 
RODRIGUES, R. R.; GRÁCIA-RODRIGUES, K. 0 ethos do jardim em Dora Ribeiro

Assim sendo, o que busca o eu-lírico? Qual o "caminho" que constitui sua trajetória, traçada na exemplaridade do poema "terreno primordial"?

A terceira e última estrofe do poema ecoa, referenda e modaliza uma das epígrafes da obra, a de Allen S. Weiss:

tem de ser móvel para a experiência do jardim. tem de se atravessar o espaço e o tempo no jardim.

(RIBEIRO, 2009, p. 7, em itálico no livro).

0 anúncio, dessa que é a primeira das duas epígrafes no pórtico da obra, é de topoi recorrentes ao longo do livro: a mobilidade inquieta, o sensível tornado experiência, a ação como um projeto, o jogo simultâneo entre espaço e tempo, e o reiterado jardim, palavra que encerra as duas frases. Ao se retornar ao texto, percebe-se que o verbo "ter", que inicia a citação, não é propositivo, não é um "tem” imperativo, é antes uma aspiração, a de "ser móvel".

A vontade enunciada visa apreender "a experiência do jardim": se o jardim é e está, como um dado existente, o sensível o apreende, torna-o algo vivenciado e incorporado ao "ser", instaurando no verbo um deslocamento que indicia o substantivo. "Ter" a experiência torna-se, talvez, "ser" o jardim. Para tanto, há que viver ("atravessar o espaço e o tempo") "no jardim" e assim dele ter "a experiência" dada pelo sensível e pela mobilidade.

Por isso, a terceira estrofe do primeiro poema, entre o presente do indicativo e o imperativo afirmativo, assim se inicia: "girassol / gira loucamente / gira". Ora, "girassol” pode ser vocativo, mas pode ser sujeito, em procedimento similar ao da primeira estrofe; se sujeito, o poema narra os atos do girassol; se vocativo, o eu-lírico determina uma ação. Na primeira estrofe, o pronome "seu" no sexto verso indica o presente e a terceira pessoa do singular como a que vigora no discurso. Sendo assim, o eu-lírico canta as ações do girassol, descrevendo seu movimento incessante e enloquecido. 
Há um motivo para a poeta voltar-se para o girassol: o giro que a flor descreve acompanhado o sol no percurso do dia significa a razão da própria existência, tal como a concebe o eu-lírico: "porque não há sentido fora / do movimento e não existe / vida fora das breves inclinações". 0 terceto que fecha o poema é construído com dois enjabements acentuadores dos complementos, cujos núcleos de sentido se efetivam pelos semas "vida" e "movimento". Assim, não há vida nem sentido fora do movimento, como não há "fora das breves inclinações".

O que vem a ser tais "inclinações"?

\section{Um primeiro traçado para o jardim}

Parece-nos que o jardim, e a teoria que - em Dora Ribeiro - o consubstancia, tem seu primeiro esboço no poema, já citado, cujo primeiro verso é "o traçado do teu jardim". A alteridade é, pois, configuradora ontológica do jardim, ou o jardim surge como subjetividade do eu lírico em seu confronto com o referente?

Intuímos que a teoria proposta pela poeta se dá por sucessivas ressemantizações do conceito de jardim. Desse modo, trata-se de jardim mítico, jardim primordial, jardim que é signo da trajetória e que é metáfora do corpo; nesse caso, como exigência de erotismo, é prenúncio do gozo. O corpo do eu-lírico surge como metonímia do mundo que se opõe ao eu biográfico, reflexo do limite entrevisto no corpo do amado:
até porque o teu corpo não me deixa pensar em nada que exceda os seus limites (RIBEIRO, 2009, p. 61).

O poema relata “a experiência da extinção" (RIBEIRO, 2009, p. 61), em diálogo que pode ser do eu com um outro amado, mas pode, também, ser do eu consigo mesmo, marcando a transitoriedade da existência pelo 
dado biográfico do poema que canta diálogo iniciado em 1960, justamente o ano de nascimento da poeta.

É existência simultaneamente móvel (em trânsito pelo jardim que é cidade, urbe) e gregária (e, nesse caso, fixada no sertão). Um poema também de cunho biográfico demarca os espaços e suas características:

\author{
o meu bisavó quis catequizar \\ os caiuá no século que \\ já era o dezanove \\ não deu certo e ele teve de \\ se virar para a homeopatia \\ devo ter copiado dele \\ a obsessão pela ideia de mudança \\ tem uma raiz parecida com a \\ que acompanha as religiões \\ exige alguma devoção cega e \\ muito exercício diluído em água \\ (RIBEIRO, 2009, p. 71).
}

0 retorno às raízes familiares em tempo de ocupação do espaço do Sertão, a cuja rudeza tenta impor a Ciência e a Religião, define o sertão como estático e a cidade como espaço do movimento. Para o eu-lírico, impôs-se a definição da vida como mudança permanente, mais um dado que a biografia da poeta homologa.

\title{
Caminhos por percorrer
}

Diante desses poemas, temos, pois, um universo poético fluido, instável, deslizante, dialético. Assim se perfaz o ethos da poesia de Dora Ribeiro, tal como se pode depreender e apreender dessa primeira aproximação de sua coletânea de poemas a teoria do jardim. A forma dos poemas indicia tal semântica: cortes bruscos nos versos, com enjabemants ines- 
perados, ausência de qualquer sinal gráfico diferencial ou marcador de ritmo (maiúsculas, pontos, vírgulas, etc.), vocativos que a releitura mostram ser sujeitos, ambiguidades lexicais e sintáticas, etc.

Desse modo, inquietações muitas latejam entremeio os corixos do Jardim e as ruazinhas do jardim, pelas ruas e edifícios da urbe, presentificação de todas as cidades do mundo, metáfora do humano aprisionado entre edifícios e consumido por engrenagens que lhe tiram do Jardim primordial para uma vida de embates inglórios. 0 corpo do sujeito vive velozmente, desde que lá no "dezanove" um bisavó pretérito vagou pelo sertão e estabeleceu-se homeopata.

Da tensão que lateja nos poemas percebemos que, na poesia de Dora Ribeiro, o limes enunciado-enunciação emerge como tensão fórica no labirinto cujos becos são epifanias re-desveladoras de vasos comunicantes entre mundos paralelos que coexistem, coalescentes, e que, opondo-se entre si, são complementares, concrescentes, indissolúveis, indivisíveis um do outro. 0 ethos dessa poesia se dá na recusa ao eu que se constrói do sujeito biográfico em tensão que delineia a fluidez do ser, o estado permanente de mudança, o gozo vivido como se sempre adiado, o Jardim feito teoria que se faz jardim, do silêncio primordial à polifonia conflagrada.

É exemplar desse percurso o último poema do livro, singularmente nomeado "resumo":

\author{
há histórias que \\ beiram a música \\ outras a impaciente \\ mola do silêncio \\ escavam olhos \\ bíblicos e terrenos \\ de ampla sordidez \\ simplesmente para \\ nada \\ difícil decidir
}


RODRIGUES, R. R.; GRÁCIA-RODRIGUES, K. 0 ethos do jardim em Dora Ribeiro

$$
\begin{aligned}
& \text { o sentido que } \\
& \text { buscam } \\
& \text { mais fácil o caudal } \\
& \text { de sinais contraditórios } \\
& \text { que cultivam na chuva } \\
& \text { (RIBEIRO, 2009, p. 92). }
\end{aligned}
$$

Os últimos versos do livro, sua última estrofe, desenham o modo de ser dessa teoria do jardim. Há, nessa poesia, uma permanente crítica ao humano que se configura, no terreno ou no bíblico, pelo sem-sentido da busca do nada; mas o ethos da poeta Dora Ribeiro é a permanente fuga em busca do indecidível: a música do silêncio.

\section{Referências biliográficas}

AZEVEDO, C. [Orelhas]. In: Dora Ribeiro. Bicho do mato (poemas reunidos). Rio de Janeiro: 7Letras, 2000.

LIMA, L. C. Intervenções. São Paulo: Edusp, 2002.

LIMA, L. C. Os jardins rarefeitos. Folha de S. Paulo. São Paulo. 9 de ago 2009. Disponível em: <http://www1.folha.uol.com.br/fsp/mais/ fs0908200905.htm>. Acesso em: 9 ago 2009.

MAURA, A. La palavra adivinatoria de Dora Ribeiro. Cronópios. Espanha. 28 abr 2012. Disponível em: < http://cronopios.com.br/site/colunistas.asp?id=5387> . Acesso em: 9 ago 2013.

RIBEIRO, D. a teoria do jardim. São Paulo: Companhia das Letras, 2009.

RIBEIRO, D. bicho do mato: poemas reunidos. Rio de Janeiro: 7Letras, 2000.

RIBEIRO, D. começar e o fim. Florianópolis: FCC, 1990. 
RODRIGUES, R. R.; GRÁCIA-RODRIGUES, K. 0 ethos do jardim em Dora Ribeiro

RIBEIRO, D. ladrilho de palavras. Rio de Janeiro: Tipografia do Jornal do Comércio, 1984.

RIBEIRO, D. olho empírico. São Paulo: Babel, 2011.

RIBEIRO, D. taquara rachada. Rio de Janeiro: 7Letras, 2002.

SANTIAGO, S. Ladrilho de palavras. Rio de Janeiro: Tipografia do Jornal do Comércio, 1894, 1므 e $2^{\underline{a}}$ orelhas.

SUSSEKIND, F. 0 dentro, o fora. Jornal de Poesia. Caderno ideias. 13 mar 1999. Disponível em: <http://www.jornaldepoesia.jor.br/fsussekind02.html>. Acesso em: 20 abr 2011. 
